Bull. Chem. Soc. Ethiop. 2014, 28(2), 187-194.

Printed in Ethiopia

ISSN 1011-3924

DOI: http://dx.doi.org/10.4314/bcse.v28i2.3

(c) 2014 Chemical Society of Ethiopia

\title{
SPECTROPHOTOMETRIC STUDY OF THE CHARGE TRANSFER COMPLEXATION OF TRANEXAMIC ACID WITH 7,7,8,8- TETRACYANOQUINODIMETHANE
}

\author{
Li Sheng-Yun ${ }^{*}$ and Hou Yu-Cui \\ Department of Chemistry, Taiyuan Normal University, Taiyuan, Shanxi 030031, China
}

(Received April 19, 2013; revised May 11, 2014)

\begin{abstract}
A simple, sensitive and accurate spectrophotometric method for the determination of tranexamic acid (TXA) has been developed. The method was based on the charge transfer reaction between TXA as $n$-electron donor and 7,7,8,8-tetracyanoquinodimethane (TCNQ) as $\Pi$ acceptor resulting in highly coloured stable complex, which showed maximum absorption band at wavelength of $419 \mathrm{~nm}$. The formation of such complex was also confirmed by infrared measurement. The stoichiometry of the complex was found to be 1:1 between donor and acceptor as determined by Job's continuous variation method and straight line method. The thermodynamic parameters were calculated as association constant $K_{\mathrm{CT}}$ of $5109 \mathrm{~mol}^{-1}$ and Gibbs free energy $\Delta G^{\circ}$ of $22.22 \mathrm{~kJ} \mathrm{~mol}^{-1}$. Different variables affecting the CT reaction were carefully studied and optimized. At the optimum reaction conditions, Beer's law was obeyed in a concentration range of 1-18 $\mu \mathrm{g} \mathrm{mL}-1$ of TXA using TCNQ reagent and the limit of detection was $0.2 \mu \mathrm{g} \mathrm{mL} \mathrm{m}^{-1}$. Different analytical parameters, namely molar absorptivity $(\varepsilon)$, relative standard deviation, correlation coefficient, limit of detection, and Sandell sensitivity, were calculated. The developed method could be applied successfully for the determination of TXA in its pharmaceutical dosage forms with a good precision and accuracy compared to the official method.
\end{abstract}

KEY WORDS: Tranexamic acid, 7,7,8,8-Tetracyanoquinodimethane, Charge transfer complex, Spectrophotometry

\section{INTRODUCTION}

Tranexamic acid (TXA) is attributed to an important hydrophilic drug of amino acid derivatives used in human medicine, which is used as an anti-fibrinolytic agent to reduce bleeding after cardiac surgery [1] and arthroplastic surgery [2], and also exhibits anti-inflammatory [3], and skin whitening effects [4]. Several methods have been reported for quantitative determination of TXA such as spectrophotometric methods [5-7], thin layer chromatography [8], high performance liquid chromatographic tandem mass spectrometry [9, 10], flow injection chemiluminescence [11], gas chromatography [12] and titrimetric method [13]. The titrimetric method is laborious, less sensitive and time consuming. The various chromatographic and chemiluminescence methods generally require complicated and expensive equipment, disposal of solvents, labor-intensive sample preparation procedure, and personnel skilled in chromatographic techniques. In this paper, we report a new spectrophotometric method for determination of TXA through charge transfer (CT) complexation with 7,7,8,8tetracyanoquinodimethane (TCNQ). The proposed method has the advantages of easy operation, high recovery, speed, and minimal use of organic solvent, and has been satisfactorily applied to the determination of this drug in pharmaceutical formulations and bulk drug.

\section{EXPERIMENTAL}

A Cary300 UV-Vis spectrophotometer (Varian, USA) was used for the absorbance measurements, using $10 \mathrm{~mm}$ path-length quartz cells. An infrared spectrometer IMPACT - 410

*Corresponding author. E-mail: lisy56@163.com 
(Nicolet, USA) was used for recording the infrared (IR) spectrum. The $\mathrm{pH}$ was measured on a 210 precise acidometer (Hanna, Italy).

All the chemicals and solvents used were of analytical reagent grade. TCNQ (Sigma Chemical Co., USA) was prepared as $1 \mathrm{mg} \mathrm{mL}^{-1}$ in acetone. The solution was found to be stable for at least 1 week at $4{ }^{\circ} \mathrm{C}$. The drug standard sample of TXA was kindly provided by Chinese National Institute for the Control of Pharmaceutical and Biological Products. The standard drug solution of $100 \mu \mathrm{g} \mathrm{mL}^{-1}$ was prepared by dissolving studied standard drug sample in water. The Britton-Robinson buffer solution was prepared by adjusting the mixture solution to $\mathrm{pH} 9.0$ using $0.2 \mathrm{~mol} \mathrm{~L}^{-1}$ of $\mathrm{NaOH}$ (A.R., Tianjin Chemical Reagent Co., China) solution, but $1 \mathrm{~L}$ of the mixture solution was made by dissolving $2.30 \mathrm{~mL}$ of acetic acid (A.R., Shanghai Chemical Reagent Co., China), $2.74 \mathrm{~mL}$ phosphoric acid (A.R., Shanghai Chemical Reagent Co., China), $2.47 \mathrm{~g}$ boric acid (A.R., Tianjin Chemical Reagent Co., China) with water in volumetric flask.

The following available commercial preparations were analyzed: (1) TXA injections (Kangpu Pharmaceutical Factory, Changzhou, China), labeled to contain $250 \mathrm{mg}$ TXA, $5 \mathrm{~mL}$ per injection; (2) TXA capsules (Sanjiu Pharmaceutical Co. Ltd., Beijing, China), labeled to contain $250 \mathrm{mg}$ TXA per capsule; (3) TXA tablets (Gannan Pharmaceutical Co. Ltd., Jiangxi, China), labeled to contain $250 \mathrm{mg}$ TXA per tablet.

\section{General procedure}

A suitable amount of the drug solution, containing 10-180 $\mu \mathrm{g}$ TXA was pipetted into a $10 \mathrm{~mL}$ volumetric flask, then $1 \mathrm{~mL}$ of TCNQ solution was added, and the solution was diluted to volume with $\mathrm{pH} 9.0$ of Britton-Robinson buffer solution and mixed thoroughly. The solution was thermostated at $40{ }^{\circ} \mathrm{C}$ of water bath for $10 \mathrm{~min}$. After rapidly cooling, the absorbance of the CT complex of TXA with TCNQ was measured at $419 \mathrm{~nm}$ against a blank solution. The calibration graph was constructed in the same way with the standard drug solution of known concentrations. The amount of TXA was computed from corresponding calibration graph.

\section{Effect of reaction conditions}

In accordance with general procedure, the conditions influencing CT reaction were optimized commonly by single factor test method, in which the studied condition was changed only. The conditions include solvent, $\mathrm{pH}$, reaction temperature and time, CT reagent concentration, the interference test, and precision.

\section{Analysis of pharmaceutical formulations}

The contents of 20 tablets or capsules of the drug (weighed accurately) were pulverized carefully with agate mortar. An amount of the powdered equivalent to the average weight of the tablet or capsule was weighed accurately and transferred into a $250 \mathrm{~mL}$ calibrated flask, dissolved in water, swirled and sonicated for $3 \mathrm{~min}$, the solution was diluted to volume with water. The first $20 \mathrm{~mL}$ of the filtrate was discarded; $10 \mathrm{~mL}$ of the continued filtrate was diluted accurately to $100 \mathrm{~mL}$ with water to prepare working solution. The absorbance of this solution was measured as described in the general procedure above.

A $5 \mathrm{~mL}$ TXA injection was transferred into a $250 \mathrm{~mL}$ calibrated flask and diluted to volume with water. A $10 \mathrm{~mL}$ aliquot of this solution was again diluted to $100 \mathrm{~mL}$ with water. This solution was also analyzed as described in the general procedure described above.

\section{Stoichiometric study}

Stoichiometry of the complex was determined by Job's continuous variation method [14]. Stock solutions of equimolar concentrations of the donor and acceptor were prepared, and made up to 
volume with $\mathrm{pH} 9.0$ of Britton-Robinson buffer solution. A series of $10 \mathrm{~mL}$ portions of master solutions of the donor and acceptor was made up comprising different complementary proportions $(0: 10,1: 9, \ldots, 9: 1,10: 0)$ in $10 \mathrm{~mL}$ volumetric flask. The absorbance of the resulting solutions was measured against reagent blanks at the wavelength of maximum absorption (419 $\mathrm{nm}$ ) after thermostating for $10 \mathrm{~min}$ in water bath that was maintained at $40{ }^{\circ} \mathrm{C}$.

Preparation of the complex for infrared measurements

To $2 \mathrm{~mL}$ of $0.05 \mathrm{M}$ drug solution, $2 \mathrm{~mL}$ of $0.05 \mathrm{M}$ of acceptor in acetone was added in a roundbottom flask containing $30 \mathrm{~mL} \mathrm{pH} 9.0$ of Britton-Robinson buffer solution and stirred for 30 $\mathrm{min}$. The solvent was evaporated under reduced pressure and the resulting oily residue was dried over calcium chloride.

\section{RESULT AND DISCUSSION}

The absorption spectrum of the reaction product between TCNQ and TXA is shown in Figure 1. The spectrum obtained for TXA/TCNQ system shows a new maximum absorption band at a wavelength of $419 \mathrm{~nm}$, which is not due to the absorption of any of the reactants and considered to be the result of CT complex formation between TXA and TCNQ. The new, low energy absorption observed in solution containing both a donor and an acceptor has been described by Mulliken [15] as CT transition involving the excitation of an electron on the donor to an empty orbital on the acceptor. This drug can be determined colorimetrically by the formation of complex with TCNQ. The absorbance of the complex was then measured at its maximum wavelength of $419 \mathrm{~nm}$. Investigations were carried out to establish the most favorable conditions for the charge-transfer formation. The influence of some variables on the reaction has been tested as follows.

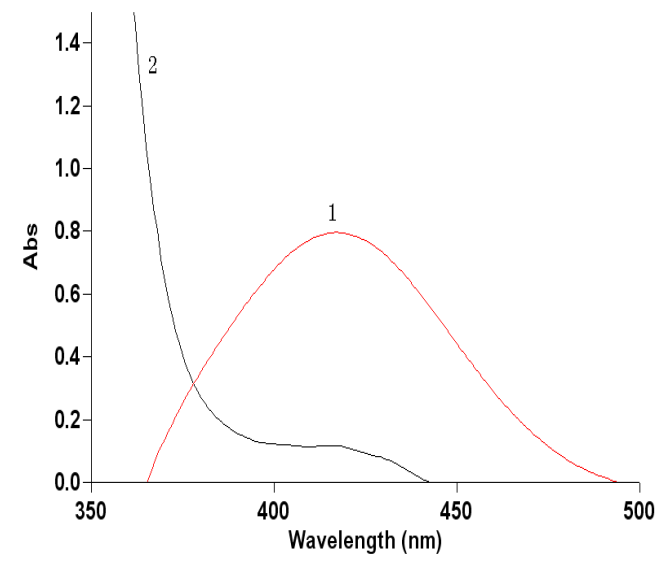

Figure 1. Absorption spectra of the complex: 1, TXA-TCNQ; 2, TCNQ. $c$ (TCNQ) $=100 \mu \mathrm{g}$ $\mathrm{mL}^{-1} ; c(\mathrm{TXA})=5 \mu \mathrm{g} \mathrm{mL} \mathrm{g}^{-1}$.

Absorption spectral characteristics of the CT complex of TXA with TCNQ in different solvents were compared. The studied solvents involved water, methanol, ethanol, acetone, acetonitrile and dimethylsulphoxide. Experimental results indicated that a mixed solvent of water-acetone at a volume ratio of water:acetone of 9:1 gave the maximum and stable absorbance of the CT complex. 
Effect of reaction temperature on the absorption of the CT complex was studied in the range of 20 to $80^{\circ} \mathrm{C}$ on a water-bath for 0 to $60 \mathrm{~min}$. The suitable temperature and time for obtaining maximum and stable absorbance were determined to be at $40{ }^{\circ} \mathrm{C}$ for $10 \mathrm{~min}$. The CT complex was stable at room temperature for at least $3 \mathrm{~h}$.

The absorption spectra of the color product-CT complex in working solutions of varying $\mathrm{pH}$ values (8.0-12.0) were recorded in order to select the optimum $\mathrm{pH}$ (Figure 2). The spectral measurements in the visible region show an increase in the absorbance with the increase of $\mathrm{pH}$ of working solution at the specific wavelength till $\mathrm{pH}$ 8.5. The absorbance was almost stable between $\mathrm{pH} 8.5$ and 10.0. At $\mathrm{pH}$ more than 10.0, the absorbance immediately decreased. So the optimum $\mathrm{pH}$ value of working solution is taken to be 9.0. But coagulation, which might result in high error, occurred in the studied reaction systems at $\mathrm{pH}$ less than 8.0 and almost no absorbance was founded in the $\mathrm{CT}$ reaction at $\mathrm{pH}$ more than 12.0.



Figure 2. Effect of $\mathrm{pH}$ on the absorbance of CT complex at $40{ }^{\circ} \mathrm{C}$ in water bath for $10 \mathrm{~min}$. TCNQ, $100 \mu \mathrm{g} \mathrm{mL}^{-1}$; TXA, $4.2 \mu \mathrm{g} \mathrm{mL}^{-1}$.

The influence of CT reagent concentration was studied in the range 50-200 $\mu \mathrm{g} \mathrm{mL}^{-1}$. The absorbance increased with increasing TCNQ concentration up to $100 \mu \mathrm{g} \mathrm{mL} \mathrm{L}^{-1}$ but leveled off at higher concentrations. Experiment indicated that $1.00 \mathrm{~mL}$ of TCNQ solution was enough for TXA, thus the final TCNQ concentration of $100 \mu \mathrm{g} \mathrm{m}^{-1}$ was accordingly used. At TCNQ concentration less than $50 \mu \mathrm{g} \mathrm{mL}^{-1}$ the absorbance was very less but there was severe interference from the background at TCNQ concentration more than $200 \mu \mathrm{g} \mathrm{mL}^{-1}$.

TCNQ is a strong $\pi$-acceptor; $n-\pi$ or $\pi-\pi$ charge transfer complexes have been reported for determination of many compounds $[16,17]$. TXA, attributed to amino acid derivative agent, has one electron rich amino group, which may form $n-\pi$ charge-transfer complex with TCNQ at the same time [18]. This drug donates probably the lone pair of electron in the $\mathrm{N}$ atom of the amino (n-electron donor) to TCNQ ( $\pi$-electron acceptor). So, CT complex can be formed with this drug. When TCNQ was added to the TXA solution, the drug solution with TCNQ caused an immediate change in the absorption spectrum with new characteristic band at $419 \mathrm{~nm}$ for TXA. The appearance of the new band in the visible region was the evidence for the possible CT complex formation of the type $n-\pi$ complex between the studied component and TCNQ. The formation of the complex was also confirmed by IR measurement. The majority of infrared measurements on the CT complex have been concerned with the shifts in the vibrational frequencies of donor or acceptor. Decreases in the vibration frequency of a particular band have been used as an evidence for a particular site of a CT interaction [19]. The IR spectra of TCNQ show strong bands at 2221,1540 , and $860 \mathrm{~cm}^{-1}$ corresponding to $v_{\mathrm{C}=\mathrm{N}}$, aromatic $v_{\mathrm{C}=\mathrm{C}}$ and $1,4-$ 
disubstituted benzene stretching, respectively. These bands were shifted in the spectrum of the complex with the investigated compound (Table 1).

Table 1. IR spectra of TCNQ and its CT complex with TXA.

\begin{tabular}{|l|c|c|c|}
\hline Compounds & $v_{\mathrm{C} \equiv \mathrm{N}}$ & $v_{\mathrm{C}=\mathrm{C}}$ & $\delta_{\mathrm{C}-\mathrm{H}}$ \\
\hline TCNQ & 2221 & 1540 & 860 \\
\hline TXA-TCNQ & 2190 & 1520 & 835 \\
\hline
\end{tabular}

Stoichiometry of the complex was determined by Job's method of continuous variations, in which master solutions of equimolar concentrations of the donor and acceptor were used in this experiment, and it was found to be 1:1 for the drug with TCNQ. Further support has been observed in the straight line method which can be used as a qualitative mean for the determination of the stoichiometry ratio of the donor and acceptor in the complex. This ratio is likely to engender owing to the presence of the nitrogen atom acting as an electron drawing group in the molecule of TXA. The nitrogen atom in amino has more electron density and less sterically hindered. So, $n-\pi$ CT complex was formed (Scheme 1).

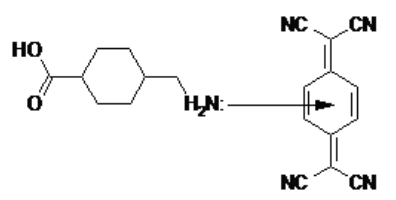

Scheme 1. The structure of amino acid derivative TXA complex with TCNQ.

The association constants for the interaction of the compound with TCNQ were estimated according to the Benesi-Hildebrand Equation when the concentration of acceptor is excess enough to regard $\left[A_{0}\right]>>\left[D_{0}\right][20]$ :

$$
\frac{\left[A_{0}\right]}{A^{\mathrm{AD}}}=\frac{1}{\varepsilon^{\mathrm{AD}}}+\frac{1}{K_{\mathrm{CT}} \varepsilon^{\mathrm{AD}}} \times \frac{1}{\left[D_{0}\right]}
$$

where $\left[A_{0}\right]$ and $\left[D_{0}\right]$ are the total concentrations of the acceptor and donor, respectively, $A^{\mathrm{AD}}$ is the absorbance of the complex at the $\lambda_{\max }, \varepsilon^{\mathrm{AD}}$ the molar absorptivity of the complex, and $\mathrm{K}_{\mathrm{CT}}$ is the association constant of the complex $\left(\mathrm{L} \mathrm{mol}^{-1}\right)$. From the previous equation, on plotting the values of $\left[A_{0}\right] / A^{\mathrm{AD}}$ versus $1 /\left[D_{0}\right]$, straight line was obtained (Figure 3 ), from which the association constants and correlation coefficient were obtained (Table 2).

$\Delta G^{\circ}$ value of the complex is calculated from Gibbs free energy of formation according to the relationship:

$$
\Delta G^{\circ}=-R T \ln K_{\mathrm{CT}}
$$

where $\Delta G^{\circ}$ is the free energy of the CT complex, $R$ the gas constant $\left(8.314 \mathrm{~J} \mathrm{~mol}^{-1} \mathrm{~K}^{-1}\right), T$ the temperature in Kelvin degrees, and $K_{\mathrm{CT}}$ is the formation constant of donors-acceptor complex $\left(\mathrm{L} \mathrm{mol}^{-1}\right)$.

The parameters thus obtained are presented in Table 2, and these values show that complexation is thermodynamically favored.

Under the experimental conditions described, standard calibration curve of CT complex for the amino acid derivative was constructed by plotting absorbance versus concentration. The linear regression equation is listed in Table 3 . The correlation coefficient is 0.9997 , indicating good linearity. The small value of variance confirmed the small degree of scattering of the experimental data points around the regression line.

Bull. Chem. Soc. Ethiop. 2014, 28(2) 




Figure 3. The curve of $\left[A_{0}\right] / A^{A D}$ versus $1 /\left[D_{0}\right]$ in TXA-TCNQ system of $\mathrm{pH} 9.0$ at $40{ }^{\circ} \mathrm{C}$ of water bath for $10 \mathrm{~min}$.

Table 2. The association constant of the complex between donor and acceptor $\left(40^{\circ} \mathrm{C}\right)$.

\begin{tabular}{|l|l|}
\hline Parameters & TXA -TCNQ \\
\hline$\lambda(\mathrm{nm})$ & 419 \\
\hline$K_{\mathrm{CT}}$ Association constant $(\mathrm{L} / \mathrm{mol})$ & 5109 \\
\hline Correlation coefficient $(r)$ & 0.9956 \\
\hline$\Delta G^{\circ}$ Gibbs free energy $(\mathrm{kJ} / \mathrm{mol})$ & 22.22 \\
\hline
\end{tabular}

${ }^{a}$ Average of five determinations.

Table 3. Quantitative parameters for CT complex of TXA with TCNQ.

\begin{tabular}{|l|l|}
\hline Parameters & TXA-TCNQ \\
\hline$\lambda_{\max }(\mathrm{nm})$ & 419 \\
\hline Beer's law limits $\left.(\mu \mathrm{g} \mathrm{mL})^{-1}\right)$ & $1-18$ \\
\hline Limit of detection $\left(\mu \mathrm{g} \mathrm{mL}^{-1}\right)$ & 0.2 \\
\hline Intercept on the ordinate $(a)$ & -0.07594 \\
\hline Slope $(b)$ & 0.09914 \\
\hline Molar absorptivity $(\varepsilon)\left(\mathrm{L} \mathrm{mol}^{-1} \mathrm{~cm}^{-1}\right)$ & $1.43 \times 10^{4}$ \\
\hline Correlation coefficient $(r)$ & 0.9997 \\
\hline Sandell sensitivity $\left.(\mu \mathrm{g} \mathrm{cm})^{-2}\right)$ & 0.011 \\
\hline
\end{tabular}

The proposed method was applied to the determination of TXA in injections, tablets, and capsules. Satisfactory results were obtained for this drug. Moreover, to check the validity of the proposed method, the standard addition method was applied by adding the pure drug to the previously analyzed tablets, capsules or injections. The recovery of the drug was calculated by comparing the concentration obtained from the mixtures with those of the pure drug. Five replicate determinations were made (Table 4). The obtained mean values \pm S.D. of the labeled amounts ranged from $95.2 \pm 2.1$ to $106.3 \pm 2.4$, the recoveries ranged from $96.2 \pm 1.4$ to $103.4 \pm$ 1.1. No significant differences were found between the calculated and theoretical values (of both $\mathrm{F}$ and $\mathrm{t}$ at $95 \%$ confidence) of both the proposed and official method, and this indicated similar precision and accuracy between proposed and official method.

Bull. Chem. Soc. Ethiop. 2014, 28(2) 
Table 4. Determination of drug in pharmaceutical formulations using TCNQ $(n=5)$.

\begin{tabular}{|c|c|c|c|}
\hline \multirow[t]{2}{*}{ Drug } & \multicolumn{2}{|l|}{ Present method } & Reference method \\
\hline & 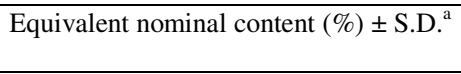 & Recovery $(\%)$ & $\begin{array}{c}\text { Equivalent nominal content } \\
(\%) \pm \text { S.D. }^{\mathrm{a}}\end{array}$ \\
\hline Pure drug & $98.9 \pm 1.2(t, 1.7 ; F, 1.0)$ & & $100.2 \pm 1.2[13]$ \\
\hline Tablet & $97.8 \pm 1.6(t, 0.4 ; F, 3.2)$ & $103.0 \pm 2.6$ & $98.3 \pm 0.9[13]$ \\
\hline Injection & $106.3 \pm 2.4(t, 0.2 ; F, 4.8)$ & $103.4 \pm 1.1$ & $106.1 \pm 1.1[13]$ \\
\hline Capsule & $103.8 \pm 2.2(\mathrm{t}, 2.3 ; F, 2.5)$ & $99.7 \pm 3.0$ & $101.2 \pm 1.4[13]$ \\
\hline
\end{tabular}

The tabulated values of $t$ and $F$ at the $95 \%$ confidence limit are $t=2.31$ and $F=6.39$. ${ }^{a}$ Average of five determinations with standard deviation.

Precision of the proposed method was determined in each concentration range, by eleven measurements carried out on different days within a week of different solution of TXA. Target concentrations corresponded to middle values of each range. Table 5 gives an R.S.D. (withinday and between-day) of solutions of certain concentrations determined by using the proposed procedure. The assay result was unaffected by the presence of excipients as shown by the excellent recoveries obtained when analyzing the drug in presence of commonly encountered excipients. As samples containing a fixed amount of the TXA $\left(5 \mu \mathrm{g} \mathrm{mL}^{-1}\right)$ and excipients $(50 \mu \mathrm{g}$ $\mathrm{mL}^{-1}$ ) were measured, no interference was observed from commonly used excipients such as starch, lactose, glucose, fructose, sucrose, and magnesium stearate. This fact indicates good selectivity of the method to determine the TXA both in raw material and in their dosage forms.

Table 5. Precision results of the proposed method $(n=11)$.

\begin{tabular}{|c|c|c|c|}
\hline \multirow{2}{*}{ Drug } & $\begin{array}{c}\text { Concentration } \\
\left(\mu \mathrm{g} \mathrm{mL}^{-1}\right)\end{array}$ & $\begin{array}{c}\text { Within-day R.S.D. } \\
(\%)\end{array}$ & Between-day R.S.D. $^{\mathrm{a}}(\%)$ \\
\hline \multirow{3}{*}{ TXA } & 5 & 1.8 & 2.1 \\
\cline { 2 - 4 } & 10 & 2.7 & 2.2 \\
\cline { 2 - 4 } & 15 & 2.7 & 2.9 \\
\hline
\end{tabular}

${ }^{a}$ Average of eleven determinations.

\section{CONCLUSION}

The results obtained from the present study indicate that $n-\pi \mathrm{CT}$ complex's formation between the amino acid derivative and TCNQ was applied in the spectrophotometric assay of tranexamic acid in its dosage forms. The proposed method can be used for the routine quality control of the pure drug and in its dosage forms without fear of interference caused by the excipients expected to be present in its dosage forms. The method has been also applied successfully to the determination of the active constituent in a commercial pharmaceutical. The proposed method has the advantages of easy operation, high recovery, speed, and minimal use of organic solvent. The investigation of real samples revealed the potential of the method in pharmaceutical analysis.

\section{REFERENCES}

1. Fiechtner, B.K.; Nuttall, G.A.; Johnson, M.E. Anaesth Analg 2001, 92, 1131.

2. Jansen, A.; Andreica, S.; Claeys, M. Br. J. Anaesth 1999, 83, 596.

3. Reynolds, J.E.F. Martindale the Extra Pharmacopoeia, 31th ed., Royal Pharmaceutical Society of Great Britain: London; 1996; pp 771-772.

4. Maeda, K.; Naganuma, M. J. Photochem. Photobiol. B 1998, 47, 136. 
5. Li, S. Y. Chin. J. Health Lab. Technol. 2005, 15, 77.

6. Wahbi, A.A.M.; Lotfi, E.A.; Aboul, E.H.Y. Talanta 1984, 31, 77.

7. Arayne, M.S.; Sultana, N.; Siddiqui, F.A.; Mirza, A.Z.; Zuberi, M.H. J. Mol. Struct. 2008, $891,475$.

8. Hosiana, B.T.; Endang, S.; Mochammad, Y. J. Liq. Chromatogr Relat. Technol. 2005, 28, 3243.

9. Bojko, B.; Vuckovic, D.; Cudjoe, E.; Hoque, M.E.; Mirnaghi, F.; Wąsowicz, M.; Jerath, A Pawliszyn J. J. Chromatogr B, 2011, 879, 3781.

10. Delyle, S.G.; Abe, E.; Batisse, A.; Tremey, B.; Fischler, M.; Devillier, P.; Alvarez J. C. Clin. Chim. Acta, 2010, 411, 438.

11. Wang, Z.P; Zhang, Z.J; Fu, Z.F; Luo, W.F; Zhang, X. Talanta 2004, 62, 611.

12. Keucher, T.R; Solow, E.B; Metaxas, J. Clin. Chem. 1976, 22, 806.

13. Editoral Committee of the Pharmacopoeia of People's Republic of China The Pharmacopoeia of People's Republic of China (Part II), Chem. Ind. Press: Beijing; 2005; pp 611-612.

14. Job, P. Ann. Chim. Appl. 1928, 9, 113

15. Mulliken, R.S. J. Chim. Phys. 1939, 7, 20.

16. Armağan, Ö. Chin. J. Chem. 2009, 27, 781.

17. Feng, X.L.; Li, N.; Zhao, F.L.; Li, K.A. Acta Chim. Sinica 2003, 61, 603.

18. Li, S.Y.; Ren, Y.Z.; Zhao, F.L. Chin. Chem. Lett. 2006, 17, 1065.

19. Foster, R. Organic Charge-Transfer Complexes, Academic Press: London; 1969; pp 51, 387.

20. Benesi, H.A.; Hidelbrand, J. J. Am. Chem. Soc. 1949, 71, 2703. 